\title{
Pedagogia da indignação: cartas pedagógicas e outros escritos
}

FREIRE, P. 1.ed. São Paulo: Editora UNESP, 2000.

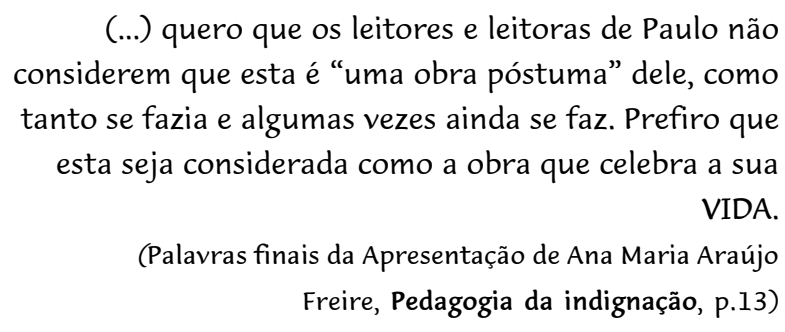

Na verdade, se a morte é inexorável, se este é o único destino certo que nos é dado, o qual não podemos mudar, portanto, nos é dado, por outro lado, o direito de celebrarmos a todos e a todas, que, na passagem pela vida humana a marcaram de alguma forma com sua presença benfazeja no mundo.

Paulo foi um desses homens que venceu o ciclo de sua vida com o mundo e se pereniza com a sua presença de VIDA entre nós pelas suas qualidades de gente e de intelectual comprometido com a Verdade, não entendida esta simplesmente como atributo do ser, como coincidência com um objeto que deve ser visto como tal ou como reflexão do ser sobre si mesmo, como correspondência, enfim. Ou ainda como revelação, sensação, evidência das coisas; como conformidade do conhecimento com as suas regras; como coerência perfeita; como o que pode ser verificável empiricamente ou demonstrável ou baseada na sua efetiva utilidade; como ciência decorrente do que pode ser comprovadamente medido e proclamado como o certo e eterno, na visão cientificista.

Falo no sentido mais rigoroso, mais autêntico e verdadeiro que podemos dar à palavra Verdade. Palavra como práxis, que, mesmo incorporando algumas dessas compreensões citadas, as supera. Falo de Verdade como uma epistemologia ontológica que possibilita fazerem-se os homens $e$ as mulheres seres autenticamente humanos. Como uma ciência político-antropológica que se preocupa fundamentalmente com o humanismo dignificador e libertador de todos os seres humanos. Como uma Filosofia Social que não se desgruda da ética humanista $e$ abomina, portanto, todas as formas de discriminação que oprimem e excluem. Falo da Verdade como Paulo a entendia $e$ praticava.

No seu ato de pensar e escrever, Paulo teve, realmente, uma capacidade extraordinária, a de ter dado unidade ao conjunto de toda a sua obra. Coerência que fez com que nunca se afastasse de suas crenças político-ideológicas e éticopedagógicas, demonstradas em cada um dos seus escritos até a sua morte. Coerência necessária a sua autenticação como pensador das liberdades dentro dos limites da Verdade que criou. Coerência nascida da condição humana de incompletude que o fez entender a esperança como algo mais do que acreditar 
num futuro melhor, mas num futuro sonhado, projetado pelas possibilidades dos homens $e$ mulheres poderem ser Seres Mais.

Em outras palavras: na sua extensa obra Paulo teve claramente a preocupação de, ao escrever cada uma delas, partir da realidade que exigia um pensar crítico e imbricá-las nos momentos históricos nos quais ele ia refletindo para nos dar meios de reflexão $e$ ação. Muitos dos temas-problema foram, entretanto, sendo re-trabalhados, atualizados com novas abordagens, aprofundados pelas suas novas leituras de mundo sempre que julgava necessário fazer isso. Teve esta prática durante todo o curso de sua vida, diante do crescimento da sua radicalidade de pensar $e$ das mudanças conjunturais ou estruturais que foram ocorrendo na sociedade. Isso denota sua lúcida percepção de tempo e espaço. De como, sem perder a coerência de seu estar com mundo, ao contrário, foi elaborando o "novo" partindo da re-elaboração do "velho", do dito e escrito por ele mesmo. Coerência que não é, pois, prender-se ao passado com medo de mudar, mas coerência que, partindo do passado, faz igualmente atualizadas as reflexões sobre os temas-problema genuinamente humanos que não devem ser esquecidos, ao contrário, devem permanecer nos fustigando crítica e esperançosamente para suas soluções. Enfim, Paulo mudou adjetivamente, mas substantivamente foi sempre o mesmo, o pedagogo dos oprimidos, o educador para a libertação.

Daí a necessidade de relermos sempre seus escritos para, contraditoriamente, lendo-os, desde os mais "antigos", os da década de cinqüenta, os do "passado", porque infelizmente ainda presente entre nós, nos atualizarmos na leitura crítica deste presente $e$, assim, termos os elementos de esperança para sonharmos os inéditos viáveis de hoje, as transformações sociais necessárias para concreta justiça, eqüidade e paz no amanhã.

Entendendo que, para celebrarmos a sua VIDA, devemos perenizar intencionalmente a sua práxis político-pedagógica, entre outras possibilidades, divulgando o seu trabalho, agrupei uma coletânea de textos seus:

Pedagogia da indignação: cartas pedagógicas e outros escritos.

Esta Pedagogia é composta de duas partes. $\mathrm{Na}$ primeira estão as Cartas Pedagógicas ${ }^{1}$, como Paulo mesmo as nomeou. Na segunda parte, os Outros Escritos, estão textos produzidos por Paulo no ano de 1996 e um de 1992, pela importância de seu tema "Descobrimento da América" no ano em que o Brasil comemorava oficialmente o seu "descobrimento".

Participam, também, deste livro, três intelectuais brasileiros, aos quais junto agora o filósofo argentino Cirigliano, todos amigos pessoais de Paulo e identificados sobretudo com o seu pensamento dialógico libertador. Destacarei, de cada um deles, o que disseram sobre a esperança e coerência em Paulo.

Um deles, outro mestre nosso, o professor Antonio Candido, escreveu para a "orelha" do mesmo, com sua permanente e serena lucidez:

De fato, é freqüente lermos e
ouvirmos que o povo não deve ser
tutelado pelas elites, devendo para isso
tornar-se ele próprio agente de seu
destino. Mas como? A pedagogia
radical de Paulo Freire aponta o
caminho com extraordinária lucidez e
coragem, ao fazer do ato educacional
um processo dialético no qual o
educando constrói o conhecimento a
partir do contexto, fundindo
aprendizagem e experiência social
numa aventura de aquisição da

De fato, é freqüente lermos e ouvirmos que o povo não deve ser tutelado pelas elites, devendo para isso tornar-se ele próprio agente de seu destino. Mas como? A pedagogia radical de Paulo Freire aponta o caminho com extraordinária lucidez um processo dialético no qual o educando constrói o conhecimento a partir do contexto, fundindo numa aventura de aquisição da

${ }^{1}$ Teriam sido de dez a 12 Cartas, como planejara Paulo, se a morte não o tivesse levado, em 02 de maio de 1997. Por isso a terceira delas ficou incompleta. 
liberdade. Por isso o seu famoso método é o das conquistas mais positivas do pensamento humanizador neste século.(...) homem que viveu intensamente as suas idéias, lutou por elas, pagou por elas um alto preço, sem temer, sem capitular, sem mudar suas convicções.

(grifos meus)

De Balduíno Andreola, que fez muito freireanamente do Prefácio do livro uma carta-resposta a Paulo, ou uma Carta-Prefácio, como acertadamente o chamou, destaco passagem de seu texto carregada de agudeza de análise e sensibilidade humanista:

Paulo, a leitura de tuas Cartas pedagógicas foi para mim como a imersão numa imensa onda cósmica de ânimo, de esperança e do sentimento de que vale a pena persistir na luta. Sinceramente há momentos em que a desesperança e a depressão parecem prevalecer. Mas ao sentir-te $e$ ao ouvir-te inteiramente fiel até o fim na tua opção de lutar, denunciando $e$ anunciando com a veemência de sempre, tais sentimentos se esvaem. (p. 18) (grifos meus)

Alípio Casali, restrito a uma pequena quarta capa, condensou impecavelmente suas idéias e nos disse com poucas palavras sobre essa unidade da obra de Paulo presente até a Pedagogia da indignação:

Toda a sua obra aqui se encurva, $e$ reencontra o essencial da educação o diálogo que compartilha e provoca (..) velhos e novos temas se entrelaçam $e$ realçam a antiga verdade freireana: não se educa sem a capacidade de se indignar diante das injustiças". (grifos meus)

Por fim as palavras de Gustavo F. J. Cirigliano, amigo trazido "de empréstimo" para esta resenha ${ }^{2}$ :

O que caracteriza Paulo Freire é a sua fidelidade consigo mesmo, sua lealdade com o próprio caminho. Não perdeu a palavra, não debandou-se para os novos tempos da globalização, do neoliberalismo e do mercado (...).

A seguir, sintetizo alguns pontos fundamentais de cada um dos ensaios contidos nesta Pedagogia da indignação, nos quais os seus leitores e leitoras poderão encontrar a tenacidade $e$ a coerência no refazer, a lucidez $e$ a esperança na sabedoria, a coragem $e$ criatividade na capacidade de ousar de Paulo.

\section{DA PRIMEIRA CARTA: DO ESPÍRITO DESTE LIVRO.}

Paulo, a tendo escrito especialmente para pais e mães, não esqueceu de contar-lhes $e$ advertir-lhes sobre a questão da autoridade $e$ dos limites inerentes a esta, do risco do ato de educar para a liberdade, relacionando-o com a inovação da história $e$ da cultura e com a possibilidade de podermos dar nomes às coisas, de decidir, perceber, escolher, valorar $e$ de eticizar o mundo. Fala-nos sobre a disciplina da vontade e da recusa à tentação da autocomplacência [que] nos forjam como sujeitos éticos. Sobre a necessidade do desenvolvimento da mentalidade democrática; da coerência; da pureza (não do puritanismo!); de negar o discurso ideológico da impossibilidade de mudar o mundo ou o discurso ideológico da inviabilização do possível; do ato de resistir e não fraquejar; da

\footnotetext{
${ }^{2}$ Em resenha sobre a Pedagogia da indignação publicada na Argentina nos jornais El tiempo, em 2 de julho de 2000 e Gaceta de la UNICEN, no. 62, de setembro de 2000, e, nas revistas Situacion, no. 8, 2000 e Vivencia Educativa, no. 125, julho 2000. (tradução minha).
} 
metodização da curiosidade. Das artimanhas do "pragmatismo" neoliberal e do treinamento no lugar da formação. De "uma das primordiais tarefas da pedagogia crítica radical libertadora [que] é trabalhar a legitimidade do sonho ético-político da superação da realidade injusta" (p.43). Declara querer transparecer com essas Cartas sua abertura ao diálogo e seu gosto de convivência com o diferente e, com sua humildade habitual, o seu gosto de ser gente!

\section{DA SEGUNDA CARTA: DO DIREITO E DO DEVER DE MUDAR O MUNDO}

Paulo escreveu logo no princípio desta Carta não ter medo dos sorrisos irônicos dos que não acreditam que mudar é difícil, mas é possível. Jamais vi, acompanhando-o nas suas "peregrinações pelo mundo" intimidar-se de dizer, pela sua coerência, cortesmente, mesmo diante de situações mais adversas, $o$ que entendia ser a Verdade. Nesta Carta diz que "os sonhos são projetos pelos quais se luta", na legitimidade do "ímpeto de rebeldia contra a agressiva injustiça" instaurada pelo secular sistema latifundiário brasileiro. Assim, fala da importância da militância do M.S.T.; da necessidade do testemunho dos educadores(as) progressistas de respeito à dignidade do outra e da outra; da diferença entre condicionamento e determinação; da ética universal do ser humano. Fala da necessidade das crianças crescerem exercitando-se no pensar, no indagar, no duvidar, no decidir, "na assunção ética de limites necessários". Termina esta Carta conclamando "Marchas" - à exemplo da dos Sem Terra que entraram em Brasília em abril de 1997 - dos desempregados; dos injustiçados; dos que protestam contra a impunidade; dos que clamam contra a violência, contra a mentira e o desrespeito à coisa pública; dos sem-teto, sem-escola, semhospital, dos renegados. " $A$ marcha esperançosa dos que sabem que mudar é possivel" (p.61).
DA TERCEIRA CARTA: DO ASSASSINATO DE GALDINO JESUS DOS SANTOS- ÍNDIO PATOXÓ

As últimas reflexões sistematizadas de Paulo nesta carta revelam toda a sua generosidade ontológica e compaixão ética pelos seres humanos que o fizeram o filósofo substantivamente humanista. Todo o seu amor pela VIDA que traduz todo o gosto que tinha de viver. Terminou-a, pois, como viveu, conclamando o amor, a justiça, a construção de uma sociedade fraterna e solidária, democrática. Expondo-se como gente, mostrando sua gentidade, como gostava de dizer:

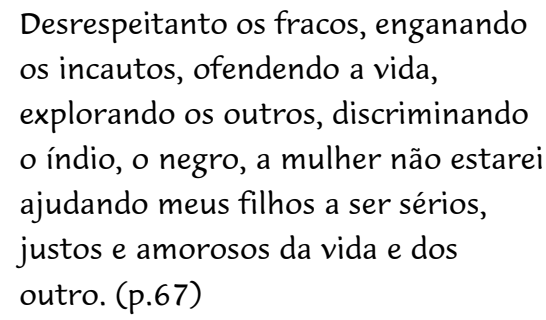

Esta Carta nos oferece, de modo especial, subsídios para reflexões sobre a ética universal dos seres humanos $e$ a valorização do diferente. Radicando-se no doloroso $e$ abominável assassinato de Galdino, o objetivo de Paulo foi nos levar a pensarmos também na questão dos valores, no modelo políticoeconômico no qual os seus defensores, de modo geral, não se perturbam como são tratadas as pessoas desprivilegiadas, as gentes excluídas do mercado, consideradas apenas "Uma espécie de sombra inferior no mundo. Inferior e incômoda, incômoda $e$ ofensiva", como denunciou.

\section{DO DESCOBRIMENTO DA AMÉRICA.}

Paulo começa afirmando que "(...)o passado não se muda. Compreende-se, recusa-se, aceita-se, mas não se muda" (p.73). Analisa o fato apontando a "malvadeza intrínseca a qualquer forma de colonialismo, de invasão, de espoliação" (p.74). Assevera que, na verdade, sofremos uma conquista, uma invasão que não deve ser amaciada numa visão crítica e que dele, nós latino-americanos, deveríamos e podemos 
tirar os ensinamentos dos e das que tiveram $e$ têm a ousadia, a coragem e a capacidade de lutar para nossa autonomia e dignidade enquanto povos e nação.

\section{DA ALFABETIZAÇÃO E MISÉRIA.}

Paulo insiste em que a realidade não é inexorável, de que de um domínio humano da determinação dificilmente se poderia falar de opções, de decisão, de liberdade, de ética. Que a história é possibilidade e não determinação. Nos faz entender que a ordem estabelecida injusta é indecente, que a "miséria é uma imoralidade" não, obviamente sob o ponto de vista moral, mas ético, estético, ontológico, antropológico e político. Afirma não por teimosia mas diante da natureza ontológica dos humanos que "mudar é difícil mas possível" e que há "legitimidade da raiva contra a docilidade fatalista diante da negação das gentes”.

\section{DOS DESAFIOS DA EDUCAÇÃO DE ADULTOS ANTE A NOVA REESTRUTURACÃO TECNOLÓGICA.}

\author{
Jamais pude pensar a prática \\ educativa, de que a educação de \\ adultos $e$ a alfabetização são \\ capítulos, intocada pela questão dos \\ valores, portanto da ética, pela \\ questão dos sonhos e da utopia, quer \\ dizer das opções políticas, pela \\ questão do conhecimento e da \\ boniteza, isto é da gnosiologia e da \\ estética. (p.89)
}

Explicita mais cuidadosamente a sua compreensão da politicidade da educação, da impossibilidade de dicotomizar ler de escrever e da unidade entre arte e educação. Enfatiza a necessidade de apreensão do objeto para a experiência cognitiva verdadeira, entendendo que a memorização do conhecimento se constitui no ato mesmo de sua produção. Critica a negação das ideologias, o neoliberalismo como 'uma fatalidade do fim do século", os pragmatismos, o treinamento no lugar da formação genuinamente humana. Alerta para a compreensão crítica das tecnologias, que não devem ser repudiadas, mas que devem ser passadas pelo nosso crivo político e ético. Re-enfatiza as suas clássicas perguntas: o quê? O para quê? O em favor de quê e de quem? O contra quê e contra quem? No exercício de pensar o tempo, a técnica e o conhecimento.

\section{DA ALFABETIZAÇÃO EM TELEVISÃO.}

Este tema, diz Paulo, nos remete à curiosidade humana e à leitura do mundo, anterior à leitura da palavra. Fala da curiosidade ingênua que leva ao "saber de pura experiência feito", o senso comum e da curiosidade epistemológica que entende nascer da criticização da curiosidade ingênua pelo rigor metodológico do objeto em questão. Entre uma e outra há diferença de qualidade e não de essência, afirma. Conclui dizendo que os educadores progressistas não podem desconhecer a televisão. Que ela não é nem "um demônio que nos espreita para nos esmagar" nem "um instrumento que nos salva”. Devemos usá-la, sobretudo, discuti-la.

\section{DA EDUCAÇÃO E ESPERANÇA.}

Paulo volta a afirmar que a vida se alonga na existência e que essa eticiza o mundo. Fala do papel da consciência humana no lugar do "ser aî" dos outros animais "aderidos ao mundo" nos dá a "responsabilidade no moverme no mundo". Da diferença entre condicionamento e determinação. Da "natureza esperançada da educação", (d)a "matriz da esperança é a mesma da educabilidade do ser humano: o inacabamento de seu ser de que se tornou consciente". Critica as concepções fatalistas da História, o poder da ideologia liberal, cuja ética perversa se funda nas leis do mercado. Reafirma sua crença de que "mudar é difícil mas é possível" e que sua luta "pelo sonho, pela utopia, pela esperança de uma Pedagogia crítica. "Esta não é uma luta vã" (p.116). 
DA DENÚNCIA, ANÚNCIO, PROFECIA, UTOPIA E SONHO.

Paulo fala da profecia e do

profeta que é o que, fundado no que vive, no que vê, no que escuta, no que percebe, no que intelige (...) atento aos sinais que procura compreender, apoiado na leitura do mundo e das palavras(...) tornando-se assim cada vez mais uma presença no mundo à altura de seu tempo, fala, quase adivinhando, na verdade intuindo, do que pode ocorrer nesta ou naquela dimensão da experiência histórico-social. (p.118)

Falava de si próprio?!. Diz que o pensamento profético é também utópico, anuncia um novo ao denunciar o velho, porque na "real profecia, o futuro não é inexorável, é problemático" (p.119). Na responsabilidade como exigência fundamental da liberdade. Critica a "política de fazer coisas" sem as perguntas fundamentais: para que? em favor de quem?..; os partidos políticos interessados em ocultar as verdades atrelados ao "rouba, mas faz". Fala do "núcleo fundamental da vida", a liberdade e o medo de perdê-la, da solidariedade e do desemprego; da violência e da necessidade da justiça para se criar a paz; das práticas negadoras da vida, entre outras, as que destroem o meio ambiente. Denuncia a transgressão da ética e a malvadez da ética do mercado. Termina o ensaio dizendo da necessidade da luta contra o desrespeito à coisa pública e contra a mentira e falta de escrúpulo, que estabelecem momentos "de desencanto, mas sem jamais perder a esperança" (p.134).

Em síntese, todos os ensaios da Pedagogia da indignação, embora com diferentes temas, estão molhados, como ele mesmo gostava de dizer, de coerência e de esperança, como também da sua mais justa raiva ou indignação, que, dialeticamente relacionada com a sua amorosidade, levam, como ele mesmo entendia, às ações éticas capazes de denunciarem o feio, o injusto e o perverso $e$ anunciarem os "inéditos-viáveis" embutidos nas utopias esperançosas, nos sonhos humanistas que deveremos tornar possíveis de democracia, de justiça e de tolerância.

Ana Maria Araújo Freire Organizadora do livro Pedagogia da indignação:
cartas pedagógicas e outros escritos.

PALAVRAS-CHAVE: Educação; cidadania; teoria pedagógica.

KEY WORDS: Education; citizenship; pedagogical theory.

PALABRAS-CLAVE: Educación; ciudadanía; teoría pedagógica.

Recebido para publicação em: 18/01/01. Aprovado para publicação em: 24/01/01. 